http://dx.doi.org/10.23925/2176-2767.2018v63p47-82

Recebido em 29/09/2018 Aprovado em 06/10/2018

\title{
ARTIGO
}

\section{8 - A DISPUTA PELO DIREITO À POLÍTICA}

\section{8- THE DISPUTE OVER THE RIGHT TO POLITICS}

\author{
CARLA REIS LONGHI*
}

\section{RESUMO}

Este artigo reflete sobre o contexto de 1968 no Brasil, a partir da análise da documentação de comunicação SNI-DEOPS/SP. A observação desta documentação demonstrou profundas alterações na tipologia, nos conteúdos e nas formas de circulação, levando-nos a ponderar sobre os seus sentidos e desdobramentos, concluindo sobre os significados de 1968 para o regime militar. Iniciamos o artigo com uma reflexão geral sobre o ano de 1968 e, a partir dos conceitos de política e cultura política, propusemos a reflexão sobre as lógicas autoritárias e sobre as estratégias discursivas utilizadas pelo regime para a manutenção do poder e do autoritarismo.

PALAVRAS-CHAVE: política; cultura política; autoritarismo; comunismo.

\begin{abstract}
This article studied the context of 1968 in Brazil, based on the analysis of the SNIDEOPS/SP communication documentation. The observation of this documentation showed profound changes in the typology, in the contents and in the forms of circulation, leading us to ponder about their meanings and unfolding, concluding on the significance of 1968 for the military regime. We begin the article with a general reflection on the year 1968 and, using the concepts of politics and political culture, we propose an analyze of the authoritarian logics and the discursive strategies used by the regime for the maintenance of power and authoritarianism.
\end{abstract}

KEYWORDS: policy; political culture; authoritarianism; communism. 


\section{Introdução}

Quando retomamos os eventos de 1968 no mundo, nos deparamos com um ponto em comum, visceral e potente: o desejo de transformar o mundo. Como colocado por Herbert Marcuse, na condição de observador / participante, "Num mundo feio não pode existir liberdade". ${ }^{1}$ Assim, variou em cada caso, em cada país, as condições de liberdade propostas, as demandas ora de caráter essencialmente político, ora culturais ou ambos; as formas de organização e associações. Mas como elemento comum, todos criticavam o sistema. Tomando o caso francês, nas palavras de Lefort:

os estudantes percebem que a formação técnica que lhes é oferecida só permitirá a um número reduzido alcançar funções de responsabilidade que requerem iniciativa, que a maior parte dos postos que disputarão pedem uma qualificação muito inferior àquela que recebem na Universidade, e, finalmente, que muitos não escaparão ao desemprego. ${ }^{2}$

O sistema impunha uma racionalidade técnica asfixiante e logo perceptível, o que levava ao questionamento do modelo econômico; do modelo de Estado; do sistema de ensino que, em última instância, significava também uma crítica à noção de conhecimento; dos valores conservadores num conflito muitas vezes geracional, constituindo o que Olgaria Matos denominou de 'A grande Recusa'.

O ano de 1968 também foi vivido no Brasil, em moldes parecidos. Em proximidade com os cenários em ebulição nos outros países, o 1968 no Brasil também não teve uma única direção e encaminhamento. Vimos uma força incontestável mas fluida na crítica aos costumes, como também, uma 
luta político-institucional canalizada na crítica ao modelo de ensino. Neste sentido, as mobilizações visíveis foram conduzidas por dois atores principais: pelos estudantes e pelos operários. Os dois casos traziam em comum a imprevisibilidade das táticas, aliás, traço próprio do 68 no mundo.

As greves operárias de Contagem e Osasco eclodiram no $1^{\circ}$. de maio, dia do trabalhador, com facetas destoantes dos movimentos anteriores, pois buscavam certa independência em relação ao comando centralizado dos sindicatos autorizados; levavam a greve para o interior das fábricas, sem destacar lideranças definidas, numa clara afronta à Lei de Greve (Lei n. 4330 de 01 de junho de 1964) que praticamente inviabilizava o direito à greve. Maria Helena Moreira Alves demonstrou que após a publicação da Lei de Greve, em junho de 1964, os movimentos grevistas diminuíram sensivelmente; se em 1962 ocorreram 154 greves e 302 em 1963, houve apenas 25 greves em 1965, 15 greves em 1966 e nenhuma no ano de 1967 e, entre estas, estavam greves bem pontuais, na luta pelo pagamento de salários, o que demonstrou a força da nova lei. Neste sentido, as greves de 1968 ganhavam enorme relevância e apontavam para a crítica à nova política de arrocho salarial que, como colocado pela autora, “...tem reiteradamente subestimado o resíduo inflacionário e os aumentos de produtividade, fazendo cair consideravelmente, em termos reais, os níveis salariais."3 O movimento não teve fôlego para reverter a condição do trabalhador, nem imprimiu imediatamente um novo perfil para a luta operária, mas teve coragem para o enfrentamento, num ambiente avesso aos movimentos sociais, demonstrando a insatisfação crescente com a política econômica imposta pelo regime militar. 
O movimento estudantil, tal qual seus pares no mundo, imprimiu como prática os eventos relâmpagos, nos formatos de comícios, passeatas, lutas de rua e ocupações. Os estudantes universitários tinham demandas próprias e relevantes como a luta pela reforma do ensino, que pressupunha a oposição à tecnicização do mesmo, tendo como contrapartida a defesa da pesquisa e visava, entre outros aspectos, o aumento do número de vagas para o ensino superior. Ao mesmo tempo, havia a luta pela autonomia da UNE, ainda clandestina, e a pressão por melhores condições de infraestrutura como a contestação ao custo da refeição universitária. Esta luta, aos poucos, se plasmou com a ação de artistas e intelectuais, ampliando a crítica e a rebeldia, regadas por shows e festivais alimentando, mais uma vez, uma crítica política e aos costumes, articulando claramente aspectos políticos e culturais.

Mas 1968 foi também, no Brasil, o ano em que o parafuso da vigilância girou mais um pouco, intensificando o controle, importante faceta da repressão. O ano começou com a publicação do Decreto-lei n. 348 em 04 de janeiro de 1968, que versava sobre o Conselho de Segurança Nacional e trazia, como diferencial da lei já existente, as funções do Secretário-Geral do Conselho, cargo este que passava a ser exercido pelo Chefe do Gabinete Militar. Tratava-se de maior regulação do funcionamento do conselho que tinha como premissa a garantia da Segurança Nacional. Este Decreto-Lei foi publicado num contexto em que outras leis referentes ao papel do cidadão e à segurança nacional já vinham sendo impostas, tecendo um cenário de institucionalização e legalização do regime através da publicação de Leis e Decretos-Leis, intensificando a vigilância e o controle. 
Assim, melhor entenderemos a importância deste Decreto-Lei se lembrarmos que o mesmo estava associado ao contexto recente de regulamentação legal. Começamos com a publicação da Constituição de 1967, em 24/01, destacando, entre muitos outros aspectos, a alteração das funções do Conselho de Segurança Nacional (CSN). A nova Constituição reforçava a responsabilidade do mesmo e já anunciava, o que seria posteriormente o Art. $1^{\circ}$. da Lei de Segurança Nacional, que criava a responsabilidade jurídica de todo cidadão pela segurança da Nação. Veremos a seguir a fundamentação desta ideia na Lei que a regulamentou. Ainda em 1967 tivemos a Lei de Imprensa (de 09/02/1967) que, apesar de não estabelecer a censura, criou restrições à liberdade de imprensa em casos considerados de atentado à moral e aos bons costumes ou que causassem perturbação da ordem pública, vinculando a produção e circulação de informação à segurança nacional e, ao mesmo tempo, fortalecendo o órgão em questão, que seria o responsável por definir o que se enquadrava na condição de risco à ordem pública. Em 25/02/67 tivemos a publicação do Decreto-Lei n. 200, alterando a composição do Conselho de Segurança Nacional, ao incorporar os chefes dos gabinetes Civil e Militar da Presidência da República, o chefe do EMFA e o chefe do SNI e ampliando suas funções. Por fim, precisamente em 13/03, foi publicada a Lei de Segurança Nacional, abaixo parcial e originalmente transcrita:

\section{CAPÍTULO I}

Disposições Preliminares

Art. $1^{\circ}$ Tôda pessoa natural ou jurídica é responsável pela segurança nacional, nos limites definidos em lei.

Art. $2^{\circ}$ A segurança nacional é a garantia da consecução dos objetivos nacionais contra antagonismos, tanto internos como externos. 
Art. $3^{\circ}$ A segurança nacional compreende, essencialmente, medidas destinadas à preservação da segurança externa e interna, inclusive a prevenção e repressão da guerra psicológica adversa e da guerra revolucionária ou subversiva. (...)

$\int 2^{\circ}$ A guerra psicológica adversa é o emprêgo da propaganda, da contrapropaganda e de ações nos campos político, econômico, psicossocial e militar, com a finalidade de influenciar ou provocar opiniões, emoções, atitudes e comportamentos de grupos estrangeiros, inimigos, neutros ou amigos, contra a consecução dos objetivos nacionais.

$\int 3^{\circ}$ A guerra revolucionária é o conflito interno, geralmente inspirado em uma ideologia ou auxiliado do exterior, que visa à conquista subversiva do poder pelo contrôle progressivo da Nação. ${ }^{4}$

Pela nova Lei aprovada, em seu artigo $1^{\circ}$, todo cidadão se tornava responsável pela segurança nacional, o que significava dizer que o mesmo deveria observar e denunciar qualquer ato considerado de risco para a Nação, tornando a delação parte da condição de cidadania. A definição e delimitação dos riscos à Nação, como indicado nos artigos $2^{\circ}$ e $3^{\circ}$, era dada pelo Conselho de Segurança Nacional que concentrava, então, grandes poderes no controle e vigilância da sociedade. $\mathrm{O}$ artigo $3^{\circ}$, em seus dois parágrafos, incorporou o conceito de guerra revolucionária, formulado pela Escola Superior de Guerra (ESG) no início dos anos 1950, reformulando o conceito de defesa e incorporando a ideia do inimigo interno e, logo, de guerra psicológica. Destacamos, por fim, que todo inquérito ou processo relacionado à segurança nacional estaria submetido aos tribunais militares ampliando, ainda mais, o campo de ação dos governos militares, numa composição de autoritarismo e militarização do Estado. Estas linhas de 
vigilância foram continuamente reforçadas num tecido já esgarçado pela Operação Limpeza, efetivada desde 1964, através dos diferentes Atos Institucionais que nortearam os procedimentos relacionados aos diferentes poderes e que já haviam garantido importantes cassações em diferentes âmbitos.

Ao recuperarmos parte da publicação das Leis e Decretos-Lei vinculados à questão da segurança nacional, pretendemos demonstrar que o percurso de radicalização da vigilância e repressão foi estruturado pari passu à proliferação dos movimentos estudantil e sindical disseminados no mesmo ano. Isto nos faz reafirmar a existência de dois projetos ou, no mínimo, duas perspectivas distintas de sociedade em disputa, questionando as argumentações que explicam e justificam a radicalização do regime em função da necessidade de contenção dos movimentos de esquerda. Entendemos, ao contrário, que projetos e utopias distintas foram gestados muito antes do golpe de 1964, mobilizando diferentes grupos em diferentes condições de organização e enfrentamentos. Nesta linha de raciocínio, o ano de 1968 apareceu como um novo round, explicitando conflitos e acirrando os enfrentamentos. Propomos aqui que a disputa maior era pelo direito à política.

\section{A busca pelo direito à política}

Os governos militares vinham desde 1964 impondo um modelo de sociedade. Com a Operação Limpeza buscaram esvaziar o cenário de oposição em todos os seus âmbitos, complementados pela publicação de Leis e Decretos-Lei que acabavam/alteravam a autonomia e poder de centros de mobilização popular, como os sindicatos e a UNE. Os 
trabalhadores foram imobilizados com a imposição de leis que os fragilizavam: o fim da estabilidade de emprego; a criação das datas-bases de negociação salarial, com a imposição de índices definidos previamente pelo governo, num processo contínuo de arrocho salarial e esvaziamento sindical. Assim, em sua face econômica, o golpe buscava garantir parte da lógica liberal, reduzindo os direitos e ganhos das classes trabalhadoras e fomentando a concentração de riqueza; neste processo, calava os trabalhadores, alijando os sindicados de sua autonomia de luta e os trabalhadores de seu instrumento de luta que era a greve.

Em termos político-institucionais, os políticos de oposição foram cassados no ato da formalização da Operação Limpeza, contabilizando 43 deputados $^{5}$ já no AI-1. O processo teve continuidade com os outros atos institucionais, estendidos aos outros poderes, com o expurgo de juízes, militares e um grande rol de funcionários públicos de todos os setores. Desta faceta visível de concentração do poder e esvaziamento da oposição destacamos também os aspectos não visíveis e simbólicos destes procedimentos, num processo de racionalização do campo político. Assim, o que pretendemos defender neste momento é que o cerceamento à política ocorreu sob formas e âmbitos distintos. Primeiramente vimos o esvaziamento da oposição, seguido da manutenção dos poderes com a centralização de sua condução e a legalização destes procedimentos com a publicação de Decretos-Lei. Ao mesmo tempo, foi se reforçando um entendimento sobre a política e seu campo, alijando-a ainda mais de sua carga combativa. Vemos, nestes procedimentos, a perpetuação ou realimentação de tipos comportamentais de nossa cultura política, aspectos 
estes que passamos a discutir a partir de dois conceitos-chave: a política e a cultura política.

Quando Jacques Ranciére discute o sentido e lugar da política, estabelece uma distinção entre política e polícia, esta última entendida não como a estrutura ou os agentes do Aparato Policial ou suas formas de disciplinarização mas “...uma regra de seu aparecer, uma configuração das ocupações e das propriedades dos espaços em que essas ocupações são distribuídas". ${ }^{6}$ O regime militar, iniciado com o golpe de1964, impôs uma lógica policial ao campo político. Os Atos Institucionais inaugurados com o golpe de 64, bem como, o corpo de leis referentes ao funcionamento dos poderes e das relações de trabalho e todo o corpo de leis referentes à segurança nacional, anteriormente citadas, configuraram o que o autor denominou como uma ocupação e distribuição dos corpos e funções que se opunham à efetividade da política. Procuramos demonstrar, por exemplo, como os trabalhadores foram cerceados em qualquer prática política, em primeira instância, pela premência da própria vida, já que era necessário trabalhar muito mais para se garantir os ganhos anteriormente certos, numa precariedade cotidiana, que obrigava concentrar todas as forças no próprio trabalho. Depois, porque não havia espaço para o questionamento às condições existentes, pelas leis que inviabilizaram as mobilizações e as associavam à segurança nacional, além do risco da demissão, em função do fim da estabilidade do emprego. E, segue o autor:

Proponho agora reservar o nome de política a uma atividade bem determinada e antagônica à primeira: a que rompe a configuração sensível na qual se definem as parcelas e as partes ou sua ausência a partir de um pressuposto que por definição não tem cabimento ali: a de uma parcela dos sem-parcela. Essa ruptura se manifesta por uma série de atos que reconfiguram o 
espaço onde as partes, as parcelas e as ausências de parcelas se definiam. A atividade política é a que desloca um corpo do lugar que lhe era designado ou muda a destinação de um lugar; ela faz ver o que não cabia ser visto, faz ouvir um discurso ali onde só tinha lugar o barulho, faz ouvir como discurso o que só era ouvido como barulho. ${ }^{7}$

A ideia de política discutida por Ranciére e aqui incorporada como pressuposto de discussão para analisarmos o contexto em questão, carrega o conflito em sua base, expondo as demandas dos 'sem-parcelas', trazendo para o cerne do sentido da política o que o autor denomina por desentendimento ou dissenso, entendimento este distinto da ideia de política como conciliação/ acomodação. Vemos que o regime militar buscou cotidianamente esvaziar a política a partir da imposição de um ordenamento legal que o legitimava ao mesmo tempo em que anulava "os sem-parcela". Estes precisavam ser calados. Mas, independentemente desta intenção, a oposição pressionava com agendas distintas, pautando suas demandas, apesar das condições desiguais de luta, garantindo o que Chico de Oliveira denominou de "um período de invenções".

Assim, entendemos o ano de 1968 como o ano de explosão dos conflitos, a explicitação da disputa pela política, não propriamente da política partidária - institucional, mas da política constituinte da condição humana ${ }^{10}$, pelo direito dos 'sem-partes' buscarem uma parte. Havia, desta forma, um enfrentamento pelos direitos formais e um forte enfrentamento simbólico, pelo direito de lutar e de transformar o espaço da política, numa clara contestação às regras e normas impostas pelo regime. Em sua dimensão visível lutavam pelo direito da existência da UNE ou dos sindicatos autônomos; pelo direito de reivindicar o espaço universitário, 
pela ampliação das vagas, com um ensino não tecnicista e só voltado para o mercado; pelo direito das liberdades individuais. Em sua dimensão não visível disputavam o espaço simbólico e como disse Morin, considerando o cenário francês, mas pertinente à outros cenários “...foi a tomada da palavra. Toda a rua falava....68 foi a brecha, todo um recalque, todo um inconsciente, todo um conjunto de coisas marginais, toda uma necessidade, toda uma libido se precipitou. Todo um questionamento nasceu." 11

Contra o direito da existência das parcelas dos sem-partes o regime militar impôs a polícia como lógica política, numa contínua intensificação de suas configurações. O desfecho do ano de 1968 foi o AI5, seguido de toda a estruturação do aparato propriamente repressivo: a OBAN depois reformulada como DOI-CODI, além da reformulação do aparato informativo. A montagem do aparato propriamente repressivo foi, mais uma vez, a expressão visível do regime autoritário, expondo seus dois pilares constitutivos: a tortura e a censura. Priorizaremos nesta exposição, seu aparato menos visível, mas, ainda assim, parte integrante da repressão, que foram as alterações processadas no âmbito da produção da informação, ou seja, seu aparato informativo. A nosso ver, este foi um importante âmbito de disputa pelo campo simbólico, reverberando seu discurso da ordem e seu protagonismo moral. Na construção e circulação da informação, o regime procurou associar o 'outro discursivo' ao inimigo, garantindo o esvaziamento da política também pela deslegitimação da fala do outro. E lembramos que o esvaziamento da política, nesta forma de procedimento, é um componente distinto do arcabouço autoritário próprio de um Estado autoritário, e justamente por ser distinto, podemos identifica- 
lo em contextos chamados de democráticos, daí a enorme importância em ponderarmos sobre estes aspectos.

\section{Culturas Políticas-Autoritárias}

Para melhor articularmos estas demandas visíveis e não visíveis e a estruturação de um entendimento de política, trabalharemos com o conceito de cultura política como chave analítica para ponderarmos sobre o cenário brasileiro. O conceito foi discutido por Rodrigo Patto, ${ }^{12}$ entre outros autores, que sinteticamente o entende como um "conjunto de valores, tradições, práticas e representações políticas partilhadas por determinado grupo humano, expressando identidade coletiva e fornecendo leituras sobre o passado..." ${ }^{13}$ Para nós, o conceito é chave para articular e/ou refletir sobre o conceito de política, aqui pautado a partir de Ranciére, como já indicado, no interior de um campo de valores, tradições e representações político- culturais constituído. Este campo carrega leituras sobre o país, numa concatenação entre referências construídas sobre a nação e discursos, práticas e representações de grupos em composição ou conflitos. O conceito viabiliza, a nosso ver, ponderar sobre uma importante lógica do comportamento brasileiro, o autoritarismo. A dinâmica autoritária pode se concretizar e se alimentar de distintas estratégias, entre as quais, destacamos e vislumbramos as estratégias de práticas claras de recrudescimento político institucional; de processos de conciliação/ acomodação no campo político-partidário institucional; ou ainda, de estratégias discursivas, representações e práticas cotidianas de acirramento moral e discurso da ordem. Neste sentido, torna-se tecido privilegiado desta 
reflexão e será dentro deste tecido que procuraremos compreender a importância das estratégias discursivas utilizadas pelos militares para a construção de sua documentação de circulação da informação.

Como colocado pelo próprio autor, a reverberação de práticas e representações se dá por vetores sociais, ${ }^{14}$ ou seja, grupos e/ou instituições como família, igreja, corporação militar, partidos, as mídias e outros, disseminando e estruturando visões de mundo. Destacaremos neste artigo o vetor mais diretamente vinculado ao regime: a corporação militar através de seus órgãos de repressão pela disseminação do discurso da ordem.

Quando analisamos a documentação de comunicação SNIDEOPS/SP notamos o percurso de constituição e intensificação da repressão e, logo, do embate, através da clara reorganização da tipologia documental. Dois aspectos distintos ganham destaque. O primeiro se refere especificamente aos tipos documentais e suas formas de circulação e o segundo diz respeito ao conteúdo predominante na documentação de circulação entre os órgãos do aparato repressivo entre os anos de 19691974. Ponderemos sobre estes dois aspectos.

Quando observamos a documentação de comunicação SNIDEOPS/SP ao longo do regime militar, notamos três grandes momentos que configuraram tipologias documentais predominantes. O primeiro momento perpassou os anos de 1964-1968; o segundo momento refere-se ao período que foi de 1969-1973 e o último período se iniciou em 1974 e seguiu até o final do regime. Aqui nos interessa a mudança processada no pós-1968, como parte de 68. Notamos que até este ano, a documentação de comunicação entre os órgãos de repressão era produzida pelo DEOPS/SP e difundida para os órgãos vinculados ao aparato repressivo e 
se caracterizava por uma variedade documental, contendo diferentes tipos de boletins informativos, recortes de jornais, documentos em que o SNI solicitava informação sobre indivíduos, grupos e/ou instituições, seguidos das respostas produzidas pelo DEOPS/SP, além de uma grande diversidade de documentos anexados, como livros, panfletos e outros. No ano de 1969 esta documentação mudou radicalmente e passou a conter predominantemente um tipo de Boletim Informativo (09/1969-07/1970), agora produzido pelo SNI para difusão para os diferentes órgãos do aparato repressivo. Esta tipologia documental foi recorrente ao longo de um ano, sendo substituída a partir de junho de 1970 por uma outra documentação específica denominada Apostila do Comunismo Internacional (06/197009/1973), também produzida pelo SNI para difusão interna.

Por que destacamos estes dois tipos documentais? Porque, a nosso ver, eles explicitam intenções, projetos e procedimentos. E aqui, o primeiro aspecto que salta aos olhos é o de que o SNI demonstrou a necessidade de ser o produtor do discurso, diferentemente do que havia ocorrido até aquele momento, ou seja, o principal órgão de repressão, diretamente vinculado ao poder executivo e existente desde 1964 só sentiu necessidade de tomar as rédeas da produção de informação no interior dos órgãos repressivos neste momento pós-1968. Isto nos faz constatar, imediatamente, o impacto representado por estes acontecimentos. Quando olhamos o perfil do documento intitulado Boletim Informativo não identificamos, imediatamente, nenhuma especificidade.

Ele [B.I.(s)] era uma documentação diária, composta exclusivamente de trechos de jornais, retirados de diferentes jornais para a composição deste novo texto. Não se tratava de um release pois não havia reescrita ou 
sintetização do texto, apenas o recorte de trechos de interesse dos agentes designados. Os Boletins estavam organizados em 4 grandes temas, subdivididos em subtemas: 1. Político (Política interna / administrativa/ externa / atividades subversivas) 2. Psicossocial (trabalho/ educação e cultura/ assistência e previdência social/ opinião pública) 3. Economia e 4. Militar. Estes quatro itens eram os âmbitos priorizados e organizados pela ESG na definição do conceito de guerra proposto pela mesma, norteador do conceito de segurança nacional observação esta que, mais uma vez, reforça a estruturação de um projeto largamente constituído em oposição à ideia de que refletia a reação à contestação social. Retomando o documento, podemos observar que sua organização interna era bem distinta do Boletim produzido pelo DEOPS/SP e visava claramente garantir uma visualização de informações referentes às áreas de interesse. Como dito, cada tema podia conter vários subitens, organizados em pequenas informações, como apresentado no documento abaixo, e seu conteúdo era sempre constituído a partir de informações jornalísticas, retiradas de distintos jornais. Observemos o exemplo e sua constituição de sentido:

\section{d. Atividades Subversivas:}

(15)- ESTELA BORGES MORATO, a policial que foi baleada em serviço quando da captura de MARIGHELA, continua internada no Hospital das Clínicas, sendo seu estado considerado gravíssimo. (FSP).

(16)- "No momento ganhamos mais uma batalha, mas é necessário vencermos a guerra.".

-A frase é de uma autoridade militar quando lhe perguntaram, ontem, se a morte de CARLOS MARIGHELA poderia significar o fim do terrorismo.

Nessa frase, está contida, também, a opinião de diversas outras 
autoridades encarregadas de combater $\mathrm{O}$ terrorismo e a subversão na área sob a jurisdição do II Ex. (ESP). (...)

(19)- As esquerdas, que estavam todas unidas, não obstante as divergências pessoais entre CARLOS MARIGHELA e CARLOS LAMARCA, agora estão completamente desarvoradas, sem liderança, com MARIGHELA morto e LAMARCA no ostracismo, quiçá foragido. Chegaram a apontar que o substituto do ex-deputado federal do comando do terrorismo seria JOAQUIM CÂMARA FERREIRA, vulgo "TOLEDO" ou "VELHO", seu lugar tenente, mas este desde 17 do mês último fugiu de SÃO PAULO para o SUL e se encontra no exterior, com passaporte falsificado, a exemplo de numerosos outros componentes da VPR. (D POP)

(20)- Surge, no caso, um episódio estranho, qual seja o comprometimento de numerosos padres dominicanos, que chegaram a instalar no convento "base fixa" das operações de CARLOS MARIGHELA e seus adeptos. Vários dos indivíduos insistentemente procurados pela polícia, com fotografias estampadas em cartazes como terroristas perigosos, já fugiram do Brasil, por interferência de um grupo de religiosos. (D POP) $)^{15}$

Escolhemos a transcrição acima pois ela é muito explícita nos elementos que desejamos destacar, o que significa que nem todo documento constituiu com tanta clareza um novo universo discursivo. Podemos notar neste BI que a sequência de informações garantiu a constituição de um novo discurso. No recorte estabelecido por nós temos, como primeira informação, a indicação do estado gravíssimo de uma policial. Sem dúvida, esta informação foi motivo de profunda consternação para os membros da corporação e até de um sentimento, quiçá, de vingança. A sequência confirmou esta impressão, pois as autoridades militares (não uma única) assumiram que ainda não tinham ganhado a guerra, mas precisavam fazê-lo; o discurso indireto presente no percurso das notas 
indica os passos dos procedimentos esperados. Os itens (19) e (20) forneceram as pistas sobre o caminho a seguir, afinal, deixaram claríssimo o fato de ocorrerem constantes fugas de terroristas, citando nomes e percurso, e de ocorrerem apoios para estas fugas, vindas de membros da Igreja.

Ao ponderarmos sobre os sentidos desta produção discursiva nesta tipologia documental entendemos, primeiramente, que se tratou de informação para autoconvencimento. $\mathrm{Os} \mathrm{BI}(\mathrm{s})$ garantiriam a manutenção de uma teia de comunicação entre os membros do sistema de Informação, alimentando o conteúdo das discussões internas, da forma desejada pelo governo, criando um sentimento de pertencimento. Esta compreensão é plausível ao considerarmos o conteúdo da informação circulante, caracterizada por recortes sintéticos de matérias já circulantes na grande imprensa. A necessidade de se estabelecer um campo de enunciação como este explicitou, por um lado, a necessidade contínua de se reforçar uma unidade da comunidade repressiva, daí indicar, também, uma contínua retroalimentação e, por outro lado, demonstrou a importância da disputa presente no campo da enunciação. João Roberto Martins Filho já indicava que passado o susto inicial do primeiro semestre de 1968, que havia forçado uma forte unidade no contexto da crise, “...no bojo da crise de 68 também os quartéis do Exército se transformaram em terreno de incontida rebeldia", ${ }^{16}$ faltando unidade dentro da Corporação Militar, fator que poderia desagregar a própria ditadura, pelo tensionamento e disputas internas. Neste sentido, este tipo documental seria uma forma de homogeneizar um discurso e, logo, buscar uma unidade maior em torno de um projeto e conduta comuns. Este tipo documental e as lógicas de sua 
constituição apontam continuamente para o tamanho da crise instaurada em 1968 que não se quer mostrar.

Esta mudança na tipologia documental veio acompanhada das alterações já indicadas no aparato repressivo, respondendo a uma remodelação de caráter geral, reformulando, ainda, seu corpo de leis para melhor sedimentá-las, como foi o caso da nova Lei de Segurança Nacional e do decreto- lei 898 de 27/09, publicado no Diário Oficial em 29/09 que reafirmavam as preocupações em relação à Segurança Nacional, destacando as aplicações penais para aqueles que pusessem em risco os interesses nacionais.

\section{O discurso do comunismo e a associação à degradação moral}

Em junho de 1970 os BIs deixaram de ser publicados e foram substituídos pelas Apostilas do Comunismo Internacional. Estas eram uma documentação de publicação mensal, muito extensa, onde apenas o sumário tinha 11 páginas. Estavam organizadas em 11 itens, cada um com vários subitens, acompanhando o movimento comunista no mundo, tendo cada continente e suas regionalidades como um tópico do sumário, além da observação dos 'movimentos religiosos e das 'Organizações Comunistas'. ${ }^{17}$ O primeiro item da Apostila, denominado ‘Assuntos Gerais’, apontava para os conteúdos priorizados em cada mês e todos os textos eram estruturados a partir da fala de um especialista externo, utilizando matérias da mídia internacional, livros publicados no exterior, discursos de representações políticas internacionais, resultados de pesquisas, principalmente na reflexão sobre as drogas, entre outros; vemos que os textos nunca eram constituídos pelo discurso propriamente militar reproduzindo, assim, uma estratégia 
discursiva largamente utilizada na imprensa para reforçar o argumento pautado pelo jornal pela exposição de uma autoridade no tema. Para este artigo, destacamos o conteúdo dos ‘Assuntos Gerais’ pois entendemos que este item, tal qual o editorial de um jornal, melhor representa as preocupações, interesses e tendências da corporação militar.

Retomando o título deste tipo documental vemos que o comunismo era o seu tema central e norteador, e, apesar deste tema ter sido recorrente em nossa história republicana, o mesmo se mantinha atual e encontrava terreno fértil nestes anos. Como demonstrou Chirio "O acirramento do clima anticomunista na esfera do mundo militar é igualmente perceptível nas 'conferências' organizadas na Aman, ${ }^{18}$ que se multiplicam a partir de maio de 1968...". ${ }^{19}$ A citação do autor aponta para o recrudescimento anticomunista em 1968, sendo ainda mais intensificado em 1969 com os enfrentamentos da luta armada. Diferentes grupos guerrilheiros atuaram ao longo destes anos, demonstrando distinções quanto à suas concepções, projetos e práticas; ${ }^{20}$ em novembro de 1969 houve a morte de Carlos Mariguela, seguida de seu sucessor, Joaquim Câmara Ferreira, em 1970, e, em setembro de 1971 morreu Carlos Lamarca. Foi neste emaranhado sangrento que ocorreu não só o início e arquivamento dos Boletins Informativos, como também, a mudança da tipologia documental prioritária, passando-se para a produção das apostilas sobre o Comunismo Internacional. A existência destas duas tipologias dentro do governo de Médici mostrou-se lógica e explicável, dado o caráter geral de ambas e o sentido tomado por este governo, representando as diretrizes da chamada linha dura, em sua busca da chamada radicalização do regime. O tema da apostila já delimitava o inimigo- o comunismo e, considerando o contexto 
da luta armada, a estigmatização deste inimigo seria esperada. O nosso interesse aqui é o de destacar a associação continua entre comunismo e a necessidade de ordem pautada pela moralidade, numa intensificação do discurso moralista.

Ao mapearmos todos os Assuntos Gerais discutidos ao longo da existência desta tipologia documental observamos a presença contínua e destacada destas temáticas aqui priorizadas em pelo menos em 65\% das publicações, distribuídas ao longo de todos os anos de produção das apostilas conformando, a nosso ver, claramente um perfil. Tomemos o tema "Subversão dos Costumes - Comunismo e Toxicomania" 21 dos Assuntos Gerais do volume de setembro de 1970 que, em seu primeiro parágrafo, colocava "Uma das armas mais sutis e sinistras do comunismo consiste em sua persistente atividade de corromper os costumes para debilitar o mundo democrático".

Destacamos este trecho inicial do documento em questão pois o mesmo explicita claramente as correlações estabelecidas entre comunismocorrupção dos costumes - mundo democrático. A definição do comunismo como o grande inimigo, como já apontado, é antiga e foi recorrente em todos os momentos de instabilidade republicana, bem como, sua associação com a degradação moral. Aqui não será diferente, chamando a atenção, a insistência e eloquência desta associação pois, como colocado por Chirio, em seu livro sobre o assunto “...os temas da destruição da família, da derrubada moral e dos estragos provocados pelo materialismo ateu não eram até 1968 centrais nas declarações públicas de militares, eles se tornam nesse momento as provas obsessivas...".22 Poderíamos nos perguntar o quanto esta produção discursiva ainda seria eficiente, mas a correlação com 
a luta armada a reavivava e fundamentava. Ao mesmo tempo, poderíamos nos perguntar, também, porque não houve a associação da ideia de degradação moral com o conteúdo disseminado pelas mídias massivas, principalmente o conteúdo de filmes norte-americanos e pelas peças publicitárias circulantes no Brasil, com a permissividade do regime. Isto porque vivíamos a abertura do mercado para o consumo de bens diversos, a difusão da mídia televisiva e a proliferação de revistas segmentadas, com grande número de peças publicitárias associadas à sedução, erotização e exposição do corpo, através da publicização de lingeries e produtos associados, como maiôs, biquínis e roupas de dormir. ${ }^{23}$ Apesar disto, a vinculação à degradação moral foi relacionada diretamente ao comunismo pois foi este o inimigo definido, construído e reconstruído pelos militares, explorado na documentação produzida pelos agentes do Aparato Repressivo para circulação interna.

Pudemos observar na totalidade dos Assuntos Gerais, a contínua vinculação entre o comunismo e a degradação moral constituída por dois grandes encaminhamentos: a disseminação das drogas e pelo uso comunista das artes em geral. A abordagem em relação às drogas apontou recorrentemente para a associação entre o seu uso e o interesse do comunismo em afrouxar os princípios morais e controlar as mentes, afirmando que sua disseminação era um projeto comunista. O conteúdo proposto procurava apresentar os riscos à saúde, com diferentes pesquisas sobre os seus componentes e efeitos no corpo; dados estatísticos sobre produção, circulação e consumo, bem como, análises geopolíticas apontando os países produtores ou receptores. 
Quanto à articulação entre comunismo, afrouxamento dos costumes e as artes em geral, partimos do trecho abaixo para analisar. Trata-se de um recorte do item ‘Assuntos Gerais’ da apostila de setembro de 1971:

O freqüentador de cinema está mais ou menos na situação de uma pessoa que foi hipnotizada. (...) ele não pode deixar de sucumbir às sugestões que invadem o vazio de sua mente. O cinema constitui um incomparável instrumento de propaganda. Daí a declaração de Lenine: 'o cinema é para nós o mais importante instrumento de todas as artes'(...) Mas, lamentavelmente, o cinema vem sendo empregado conscientemente na dissolução dos costumes tradicionais do mundo democrático livre. Ocidente?

E o que estamos vendo hoje nas democracias do

Presenciamos o afrouxamento das idéias religiosas, dos princípios morais, dos vínculos de família, através de filmes e peças teatrais, oriundos da literatura perniciosa. Tudo isto levando a um objetivo calculado e frio: a deteriorização de todos os valores humanos, enfim a putrefação social de um país. (...)

Como pôde acontecer isso?

A explicação ultrapassa os limites deste trabalho, mas pode ser resumida nisto: os adeptos de Marx vêem armas ou meios de ataque onde outros povos vêem apenas instrumentos de relação pacífica entre os homens. (...)

Assim, uma Nação soberana pode ser solapada e até destruída por ações subterrâneas - tipo cavalo de Tróia - e que não podem ser caracterizados diante das leis tradicionais como atos de agressão. Povo e território agredidos por processos invisíveis acabam por render-se à vontade do Estado agressor, sem que este possa ser incriminado com provas positivas.

É missão, pois do Estado velar cuidadosamente pela defesa dos alicerces fundamentais em que repousa a consciência Nacional, combatendo por todos os meios os pontos de infiltração sutil, o trabalho demolidor que, dificilmente, poderiam ser hoje caracterizados como atos de agressão, embora na 
realidade sejam perigosas armas de destruição subterrâneas dos Estados. (...)

E quando intelectuais vierem a público declarar que o 'cinema novo' no Brasil está sofrendo cerceamento de sua liberdade criadora, reforçando o seu ardiloso argumento que o nosso país vem conquistando ultimamente prêmios internacionais, é preciso tapar-lhes a boca com a verdade, infelizmente muito pouco conhecida:

A maioria dos festivais, (ou quem sabe, a totalidade) que se realizam por esse mundo afora (Europa principalmente), estão sob disfarçado, mas rigoroso controle dos comunistas. ${ }^{24}$

A degradação moral foi apresentada como um projeto minucioso e extenso que visava, em primeira instância, fragilizar as instituições sociais ordenadoras da moral e bons costumes, como a família e a Igreja. É importante lembrarmos que estas duas instituições vinham se sentindo pressionadas pela juventude universitária, pelos trabalhadores, por setores artísticos, através da produção disseminada pelos polos de reflexão e produção artístico-cultural como o CPC (Centro Popular de Cultura) e o MCP (Movimento de Cultura Popular) do Recife e, fundamentalmente, pelos governos considerados populistas, no caso o governo de Jango, desde o início dos anos de 1960. Esta tensão foi intensificada com o golpe de 1964, mobilizando estes setores no questionamento ao Estado e ao projeto político pensado para o país e demonstrando forte acirramento no campo dos costumes, claramente constatados pelos movimentos denominados 'Marcha da Família com Deus pela Liberdade', ocorridos entre 19 de março e 8 de junho de 1964 .

O ano de 1968 representou, como já dito, a explicitação das tensões e enfrentamentos e vemos o regime respondendo à estas pressões através de diferentes estratégias discursivas. A primeira que destacamos foi o 
fomento às instituições da ordem, visando a manutenção da estrutura e hierarquia social, ou seja, a manutenção do autoritarismo social. Quando retomamos o conceito de autoritarismo discutido pelo dicionário de Política, vemos:

Neste sentido, o pensamento autoritário não se limita a defender uma organização hierárquica da sociedade política, mas faz desta organização o princípio político exclusivo para alcançar a ordem, que considera como bem supremo. Sem um ordenamento rigidamente hierárquico, a sociedade vai fatalmente ao encontro do caos e da desagregação. (...) Para a doutrina autoritária, a organização hierárquica da sociedade acha a própria justificativa em si mesma e a sua validade perene. Além do mais, o Autoritarismo, como ideologia da ordem, se distingue de forma clara do próprio totalitarismo fascista, já que ele apenas impõe a obediência incondicional e circunscrita do súdito e não a dedicação total e entusiástica do membro da nação ou da raça eleita." 25

A definição de autoritarismo está umbilicalmente vinculada ao ideário da ordem, considerado um bem supremo e tendo a organização social hierárquica como o princípio para o seu êxito. Assim, a estratégia discursiva das apostilas, ao mesmo tempo em que reafirmou recorrentemente o princípio da ordem e, logo, da organização hierárquica da sociedade garantiu, também, o apoio de importantes polos geradores e replicadores de discursos, reforçando um comportamento introjetado na cultura brasileira.

Ao mesmo tempo em que reafirmou a ordem e a hierarquia, tensionou a sociedade através da polarização e do medo, ao associar as críticas políticas, culturais e geracionais à difusão do comunismo. Nesta estratégia discursiva os governos militares, através de seus agentes do 
aparato repressivo, vincularam a criação artística e a crítica social ao maior inimigo nacional existente, criado e lapidado ao longo das décadas anteriores - o comunismo, esvaziando a efetiva crítica político-cultural contida nestas manifestações. A associação entre degradação moral e comunismo justificava, então, a intensificação da lógica autoritária, na figura da Doutrina de Segurança Nacional e Desenvolvimento Econômico, doutrina esta central para a constituição do próprio Estado, contribuindo para o fortalecimento do conceito de guerra norteador desta mesma doutrina. Assim, a ideia de degradação moral vinha de encontro à concepção de guerra interna, já consumada na legislação de 1967. Nesta lógica, se o comunismo se alastrava por todos os âmbitos da sociedade, como um fantasma sem rosto, atingindo as pessoas nos momentos de seu lazer, quando podiam 'baixar a guarda', justificava a necessidade do controle e o acompanhamento constante de todos os passos de todos os setores da sociedade.

Este binômio nos remete à reflexão sobre as ideologias circulantes e os ideários constitutivos de nosso pensamento autoritário. Apesar de sabermos que esta discussão não se encerra aqui, pois é ela que nos autoriza a observar minuciosamente a documentação produzida pelo regime, buscando em sua terminologia, em seus temas recorrentes, em sua formalização seu caráter específico, podemos desenvolvê-la através da análise dos aspectos formais e imediatos que o regime militar nos oferece a partir do golpe que o institui. Nesta perspectiva, o binômio Segurança Nacional e Desenvolvimento é elucidador, pois ele alimenta a longa tradição do pensamento autoritário brasileiro, centrado na ideia de “Ordem” já discutida, aqui através da palavra "Segurança”". 
No procedimento apontado, de associação direta entre produção artístico-cultural e disseminação do comunismo, colocou todo o campo da produção artística em suspeição garantindo, por um lado, a inviabilidade do direito à crítica contidos nestas produções e manifestações e, por outro lado, novas justificativas para o controle e cerceamento destes setores. Não seria excessivo lembrarmos que o campo cultural aparecia como um importante âmbito de resistência e oposição ao regime e a associação proposta se mostrava muito produtiva pois viabilizava a repressão e controle dos setores e obras que interessasse. ${ }^{26}$ Como este, vários outros documentos apontavam para a disseminação comunista através da utilização de todos os campos da produção cultural, chegando ao cidadão comum pelas revistas, jornais, literatura, cinema, televisão e música, como na apostila de 04/72 que afirmava que o comunismo difuso estava presente na realidade brasileira à pelo menos dez anos com diferentes objetivos, entre eles "1. Degradar todas as formas de expressão artística; fazer desaparecer todas as leis que refreiam a obscenidade (...) nos livros, jornais ilustrados, cinema, radio e TV"(CI- 04/72)".

\section{Enunciação e esvaziamento da política}

Considerando as articulações discursivas que associavam comunismo - degradação moral e logo, risco da ordem no momento em que foram proposta, vemos o contexto de 1968 como aquele que pôs em risco o projeto autoritário construído ao longo da ditadura ao pautar demandas e impor procedimentos que questionavam não só a lógica autoritária do Estado como também, a lógica autoritária da sociedade, ao questionar padrões de comportamento, costumes, noções de liberdade, pressionando pelo direito ao corpo e pelo direito à fala e à política. Pôs em 
risco, também, a estabilidade da própria Corporação Militar pelos acirramentos no interior da mesma, onde havia claras divergências quanto aos encaminhamentos necessários para o controle social. Mostrou-se, assim, muito sintomática a necessidade de reafirmar valores e costumes, numa a estratégia de associação ao comunismo, com contínua retroalimentação.

Nesta lógica discursiva, encontramos ainda dois outros aspectos dignos de reflexão: o lugar de enunciação construído pelos agentes do aparato repressivo para os militares e para os estudantes universitários. Ao associarem degradação moral ao comunismo procederam, também, à reafirmação do lugar do militar na construção moral e, ao mesmo tempo, à degradação da juventude e sua associação direta ao terrorismo. Houve aqui, novamente, uma estruturação discursiva dicotômica, situando o bem e o mal própria, aliás, da lógica hierárquica. Os bons eram os militares, que assumiam a responsabilidade pela reconstrução ou manutenção moral, ação esta própria da Corporação Militar. Neste procedimento, os detentores da enunciação procuraram reafirmar o tradicional lugar desta corporação como representantes da ordem e da moralidade. De diferentes maneiras este lugar social do militar como o arauto da moralidade, da ordem e da responsabilidade pela grandeza da Nação, foi construído e disseminado ao longo de toda a república, através da imprensa, da própria academia e de seus próprios discursos, inclusive os discursos constituintes de toda a memória militar.

Retomamos aqui um documento constante do acervo documental aqui trabalhado que reverbera esta mesma lógica. Trata-se de um documento produzido por militares, que não se identificaram 
nominalmente, mas assinaram como 'Frente Militar Revolucionária'. O documento foi escrito em 1956 e certamente refletiu o contexto da eleição de Juscelino Kubitschek pois, como todos sabemos, foi um momento de crise institucional e tentativa de golpe militar para evitar que o mesmo assumisse, já que foi vitorioso no processo eleitoral. O golpe não se efetivou pois não havia unidade interna e nem todos os setores militares apoiaram o golpe, criando uma grande fissura interna. Retomamos documento de período anterior ao trabalhado neste texto, pois o mesmo demonstra a continuidade quanto a aspectos do pensamento político, reforçando nossa reflexão a partir do conceito de cultura política:

1. A Frente Militar Revolucionária obedece a princípios definidos e visa finalidades pré-determinadas, incidindo e se desenvolvendo num plano mais vasto, capaz de firmar a mística em torno da qual se conjuguem todos os esforços. Esta mística é a da formação de um Brasil grande, próspero e feliz, para o que devemos objetivar a elevação do nível moral e político da nossa gente, o aperfeiçoamento das nossas condições sociais e econômicas e o enobrecimento de nosso civismo. Para alcançar esses fins, devemos conjugar os nossos esforços e termos a convicção de que o nosso futuro está na dependência de nossa vontade. É preciso ter consciência de que o caminho é longo e árduo e de que são enormes os obstáculos a superar, visando tais finalidades. Mas temos fé em que os brasileiros saberão descobrir, em seu íntimo, as energias necessárias a vencer todos os óbices.

2. O nosso movimento não é um partido político; não representa uma agremiação política. É um movimento de reconquista da autoridade nacional e da harmonia das classes divididas. ${ }^{27}$

Notamos, então, em documento de 1956 a associação entre as ideias de grandeza nacional- aprimoramento moral- papel dos militares neste processo, reafirmando continuadamente o virtuosismo da Corporação 
Militar e sua responsabilidade político-social. Vemos, ainda, a relação com a necessidade de fortalecimento da Nação e apaziguamento dos conflitos de classe e esta mesma condução também está presente nas formulações das apostilas do Comunismo Internacional.

Ponderaremos, agora, sobre a construção das representações sobre o estudante universitário, ator este central no contexto de 1968. Para tanto, partiremos de mais um trecho das apostilas sobre o comunismo, no recorte presente na apostila de junho de 1971:

Percebe-se nestes depoimentos a reprovação às orgias alcóolicas e sexuais (1) que ocorrem entre os elementos engajados na subversão. Diversos destes depoimentos vêm comprometendo sistematicamente as lideranças mais conhecidas e atuantes do terror, demonstrando que o engajamento de novos contingentes para a luta não vem alcançando índices esperados.

(1)Declaração de José Gercino Saraiva, ex-militante do PCBR “a degenerescência e a corrupção são inimagináveis, tais os meios e os processos escusos de que usam os 'cabeças' e os antigos no trabalho de subversão no Brasil. A prostituição e as perversões campeiam. Conheci moças, tidas como líderes do movimento terrorista, que participaram em ações de assaltos a bancos, que viviam maritalmente até com seis homens do nosso meio e se vangloriavam disso. Dirse-ia que tinham perdido todo o pudor, depois de passarem nos cursos de subversão ministrados até por elementos vindos do exterior. ${ }^{28}$

O documento transcrito é muito explícito em demonstrar a contínua associação discursiva proposta pelos militares que identificava na juventude universitária o polo norteador da degradação moral, degradação esta instada pelos comunistas. Neste processo, em primeiro lugar, os estudantes eram imorais, propagando obscenidades, desrespeitando instituições e destruindo os valores tradicionais. Em segundo lugar, os estudantes 
tornaram-se terroristas, por serem o instrumento de difusão do comunismo. Este segundo aspecto justificava as prisões, torturas e mortes, no escopo da guerra revolucionária para a defesa da Nação.

Este percurso de construção atrelou, também, as concepções de ensino ao risco comunista, buscando acabar com propostas de ensinos de cunho libertário ou humanista que traziam como eixo central a autonomia do sujeito, o que também abria a possibilidade para o endurecimento dos modelos de ensino tradicionais. Na apostila do CI da virada do ano de 1972 encontramos um documento sobre o Movimento de Educação de Base, anexado à pasta “ “... os organizadores do MEB, utilizando como ideia força 'o cooperativismo', estão aplicando, nos participantes do curso em questão, as técnicas preconizadas pela Guerra Revolucionária, de modo a provocar antagonismos e fomentar as lutas de classes". ${ }^{29}$

É interessante que o mote da argumentação foi a ideia de cooperativismo; vale lembrar que cooperativismo e solidariedade foram os eixos constituintes das formulações anarquistas e anarco-sindicalistas presentes no início do século XX, então associadas à radicalização de esquerda. O documento é bastante longo, narrando a gravação integral de duas aulas do MEB e foi finalizado com o seguinte parecer “... as atividades do MEB ultrapassam a simples e meritória condição de um movimento educacional de interesse do Estado, para tornar-se eficiente instrumento de proselitismo comunista...".30

\section{Considerações finais}

Retomando o todo deste artigo, gostaríamos de ponderar sobre estas articulações discursivas presentes na documentação de comunicação do 
SNI-DEOPS/SP aqui apresentadas e os sentidos produzidos em e sobre 1968. Concordamos com Morin quando colocou sobre o cenário francês:

Maio de 68 ensinou que o subsolo da sociedade está minado. Antes de 1968, vivíamos em uma sociedade que acreditava repousar em terreno sólido, maciço. A sociedade industrial triunfava, era capaz de resolver todos os problemas fundamentais do homem moderno- a fome, a miséria, a servidão. ${ }^{31}$

No contexto brasileiro o golpe de 1964 já havia apontado para a constatação do solo minado e como a sociedade industrial não havia resolvido questões de base. Estas mesmas questões foram intensificadas entre 1964-68, como apontado ao longo do texto, explodindo em 1968. Assim, o ano de 1968, no mundo, demonstrou que a insatisfação era sistêmica, sobre o todo da sociedade e isto não foi diferente no contexto brasileiro. Como já discutido ao longo do texto, as demandas dos movimentos estudantis e operários demonstravam necessidades concretas, bem como discordavam das visões de mundo e projeto de Estado em vigor, trazendo grande carga utópica mobilizadora. Dentro deste cenário procuramos demonstrar um âmbito destes confrontos, o âmbito dos embates simbólicos e suas construções discursivas, demonstrando distintas estratégias e táticas, procurando apresentar também a força destes movimentos não pelo que conquistaram, que foi irrisório ou nulo, mas pelo que provocaram como reordenamento e impacto discursivo e simbólico. Assim, a ideia aqui desenvolvida foi a de que a força da reação do regime contra os significados de 1968 demonstram a força que se quer negar do próprio momento. A nosso ver, foi muito sintomática a preocupação dos agentes do SNI em tomar as rédeas da produção discursiva de difusão 
interna, pela produção de uma extensa e densa documentação, que vigorou por quatro anos, como documentação predominante, trazendo a preocupação central em fortalecer a tese do inimigo interno, na figura do comunismo associado, como discutido, à degradação moral, produzida intencionalmente pelos comunistas e disseminada pelos estudantes. Assim, buscamos destacar um âmbito de confronto simbólico, onde uma importante questão era a manutenção de uma estrutura autoritária de sociedade, cujos pilares eram a moral e a ordem.

Como visto, este enfrentamento era capaz de, ao mesmo tempo, desqualificar o oponente, identificando-o com o inimigo e, como inimigo, reafirmando o lugar de fala dos militares, como a instituição capaz de garantir o sustentáculo moral e, logo, a ordem. Como pano de fundo estava a manutenção da sociedade autoritária, hierarquizada, que submetia os sujeitos e não discutia condições e conflitos de classe, intensificando as distâncias sociais e a concentração de renda.

Em nosso entendimento, o contexto de 1968 pôs em risco o projeto autoritário construído ao longo da ditadura ao pautar demandas e impor procedimentos que questionavam não só a lógica autoritária do Estado, como também, a lógica autoritária da sociedade, ao questionar padrões de comportamento, costumes, noções de liberdade, pressionando pelo direito ao corpo e pelo direito à fala. Mostrou-se muito sintomática a necessidade de reafirmar valores e costumes e a estratégia foi a de associá-las ao comunismo, inimigo este certo e inquestionável.

Ponderando sobre o título proposto para este artigo, diríamos que o grande mote de 1968 foi a disputa pelo direito à política, no sentido largamente discutido aqui a partir de Ranciére. E, justamente, as estratégias 
utilizadas pelo regime foram de mais uma vez calar a política e impor a polícia, em todos os seus sentidos: no sentido concreto, pela estruturação do aparato propriamente repressivo a partir de 1969 e no sentido simbólico pela desqualificação da fala do outro, na associação com o inimigo.

A estratégia, no momento em questão, foi parcialmente vitoriosa pois as conquistas não ocorreram e o discurso da moral foi revigorado. Por outro lado, dois outros desdobramentos apontaram para a vitória parcial e a manutenção da tensão, do campo minado apontado por Morin: a proliferação de movimentos sociais, a partir do início dos anos 1970 e a constituição da memória do vencido como a memória vitoriosa. Os movimentos sociais, intensificados a partir de 1975, demonstraram as enormes fissuras que permaneceram. Ao observarmos estes movimentos, imediatamente percebemos a difusão das questões presentes em 1968. Os movimentos feministas, movimentos de negros, movimentos de homossexuais (ainda não denominados LGBT) carregaram e carregam questões vinculadas ao direito à prática política, bem como ao direito às liberdades individuais e questionamento da moralidade imposta. Devemos destacar também a vastidão de movimentos vinculados aos direitos e demandas do cotidiano que tiveram o enorme papel de redimensionar lugar do cotidiano, alçando-o ao lugar da prática política, forçando a intelectualidade acadêmica a considerar conceitualmente o cotidiano como âmbito de prática política. Este cenário riquíssimo aqui apenas indicado, demonstra a profundidade das tensões e redimensiona o lugar da política. 


\section{Notas}

* Doutora em História Social pela Universidade de São Paulo. Pós- Doutora em Comunicação Social pela Universidad Complutense de Madrid. Coordenadora do PEPG em História da PUC/SP. Professora Concursada do Depto. de História da Pontifícia Universidade Católica de São Paulo e Professora Titular do Programa de Pós-Graduação em Comunicação Universidade Paulista. E-mail: carlalonghi@,uol.com.br / ORCID: https://orcid.org/0000-0003-2937-8982

${ }_{1}^{1}$ Frase proferida por Marcuse para a revista Spiegel em 1967 e recuperada na entrevista que compõe o livro COHN, S.; PIMENTA, H. Maio de 68 Encontros. Rio de Janeiro: Beco de Azougue, 2008. p. 90.

2 MATOS, O. Paris 1968 - As Barricadas do Desejo. São Paulo: Editora Brasiliense, 1998. p. 21.

${ }^{3}$ ALVES, M. H. Estado e Oposição no Brasil. Petrópolis: Editora Vozes, 2005. p. 95.

4 Lei de Segurança Nacional publicada em 13/03/1967. Disponível em: http://www2.camara.leg.br/legin/fed/declei/1960-1969/decreto-lei-314-13marco-1967-366980-publicacaooriginal-1-pe.html

${ }^{5}$ ALVES, M. H. op. cit..

${ }^{6}$ RANCIÉRE, J. O Desentendimento: política e filosofia, São Paulo: Editora 34, 1996. p. 42.

7 Idem.

${ }^{8}$ MOTTA, R. P. S. Cultura política e ditadura: um debate teórico e historiográfico. Tempo e Argumento, Florianópolis, v. 10, n. 23, pp. 109-137, jan/mar.2018.

${ }^{9}$ No artigo intitulado "Das Invenções à Indeterminação" Francisco de Oliveira compara três momentos da história recente do Brasil vendo, no período do regime militar, uma era de invenções ao contrário do período governado por FHC visto como um período de indeterminação. O eixo mobilizador de sua reflexão foi o da observação da prática política nestes três momentos, a partir do conceito de política como dissenso. Podemos notar que sua reflexão caminhou na avaliação de uma perda da capacidade política no período democrático. OLIVEIRA, F. Das Invenções à Indeterminação. In: OLIVEIRA, F.; RIZEK, C. (Orgs). A Era da Indeterminação. São Paulo: Boitempo, 2007.

10 ARENDT, H. A Condição Humana. Rio de Janeiro: Forense Universitária, 2000. Indicamos a leitura de Hannah Arendt, em seu livro A Condição Humana, que propõe o conceito como constituinte da condição humana.

${ }^{11}$ MORIN, E. O Jogo em que tudo mudou. In: COHN, S.; PIMENTA, H. Maio de 68 - Encontros. Rio de Janeiro: Beco de Azougue, 2008. pp. 34-35.

$12 \mathrm{O}$ autor escreveu diferentes textos discutindo o conceito. Certamente, pelo tempo dedicado ao mesmo neste artigo, incorreremos no risco de simplifica-lo em demasia e, por isto, sugerimos as leituras já indicadas nas citações, além do artigo: 
MOTTA, R. P. S. Universidades, ditadura e cultura política. Revista Interseções, Rio de Janeiro, v. 16, n. 1, pp. 69-89, jun. 2014.

${ }_{13}$ MOTTA, R. P. S. Cultura política e ditadura: um debate teórico e historiográfico. Tempo e argumento, Florianópolis, v. 10, n. 23, pp. 109-137, jan./mar. 2018, p. 114.

${ }^{14}$ MOTTA, R. P. S. Desafios e possibilidades na apropriação de cultura política pela historiografia. Disponível em http: ///E:/1968\%20NO\%20BRASIL/Desafios_e_possibilidades_na_apropriacao\% 20da\%20cultura\%20política-\%20RODRIGO\%20pATTO.pdf

${ }_{15}$ Pasta 20.C.043- 004, doc. 298, BI n. ${ }^{\circ} 259,06 / 11 / 69$.

16 MARTINS FILHO, J. R. O Palácio e a Caserna: a dinâmica militar das crises políticas na ditadura (1964-1969). São Carlos: EDUFSCar, 1995. p. 143.

17 Os itens eram: 1. Assuntos Gerais; 2. Movimento Religioso; 3. Potências Comunistas; 4. Ásia e África; 5. Europa Oriental; 6. Europa Ocidental; 7. América do Norte; 8. América Central; 9. América Latina; 10. América do Sul; 11. As Organizações de Frente Comunistas.

18 A Aman - Academia Militar das Agulhas Negras - foi criada em dezembro de 1966.

${ }^{19}$ CHIRIO, M. A Política nos Quartéis: revoltas e protestos oficiais na ditadura militar brasileira. Rio de Janeiro: Zahar, 2012. p. 119.

${ }^{20}$ RIDENTE, M. O Fantasma da Revolução Brasileira. São Paulo: Editora Unesp, 2010. Nesta obra o autor traz uma apresentação precisa sobre as diferentes organizações revolucionárias, bem como, suas formas de luta e seus embasamentos ideológicos.

${ }^{21}$ Pasta 20.C.043- 021, CI o9/70.

${ }^{22}$ CHIRIO, M. op. cit., p. 121.

23 GELLACIC, G. B. Despindo Corpos - sexualidade, emoções e novos significados do corpo feminino no Brasil entre 1961 e 1985. Tese, PUC/SP, São Paulo, Brasil, 2014. A pesquisa de Gisele B. Gellacic traz uma reflexão muito interessante sobre este aspecto. Em sua tese a autora discutiu a sexualidade feminina entre 1961 e 1985 através da análise de duas revistas femininas- Claudia e a Nova. Sem ser o foco central de sua pesquisa, demonstrou a postura dicotômica do governo Médici que estabeleceu censura aos textos das revistas (entre os anos de 1970/71), mas permitiu a circulação das peças publicitárias que expunham um corpo erotizado.

${ }^{24}$ IDEM - 030, doc. 3547, CI n. 9/71.

25 BOBBIO, N.; MATTEUCCI, N.; PASQUINI, G. Dicionário de Política, Brasília: Editora UNB, 1999. p. 95.

${ }^{26}$ Sobre a atuação do regime militar em relação ao campo artístico-cultural, ler Marcos Napolitano. O autor produziu diferentes artigos sobre o tema, com distintas abordagens, demonstrando as formas de relação estabelecidas pelo regime com o campo artístico, além de discutir a complexidade do próprio campo. Sugiro neste momento o capítulo "Vencer Satã só com orações": políticas culturais 
e cultura de oposição no Brasil dos anos 1970" In: ROLLEMBERG, D.; QUADRAT, S. (Orgs). A Construção Social dos Regimes Autoritários. Rio de Janeiro: Civilização Brasileira, 2011.

${ }_{27}$ Pasta 20.C.02- 002, doc. 196, 1956.

${ }^{28}$ Pasta 20.C.043-026-A, doc. 3144, CI n. 6 de junho de 1971.

${ }^{29}$ Pasta 20.C043-027, doc. 3222. Nov/71 - Jan/72

30 idem.

${ }^{31}$ MORIN, op. cit., p. 34. 